\title{
Versatile guideline-based physiotherapy intervention in groups to improve gait speed in Parkinson's disease patients
}

\author{
Kadri Medijainen ${ }^{\mathrm{a}, *}$, Mati Pääsuke ${ }^{\mathrm{a}}$, Aet Lukmann ${ }^{\mathrm{b}}$ and Pille Taba ${ }^{\mathrm{c}}$ \\ ${ }^{a}$ Institute of Sport Sciences and Physiotherapy, University of Tartu, Tartu, Estonia \\ ${ }^{\mathrm{b}}$ Department of Sports Medicine and Rehabilitation, Institute of Clinical Medicine, University of Tartu, \\ Tartu, Estonia \\ ${ }^{\mathrm{c}}$ Department of Neurology and Neurosurgery, Institute of Clinical Medicine, University of Tartu, \\ Tartu, Estonia
}

\begin{abstract}
.
BACKGROUND: Gait function is known to be impaired by Parkinson's disease (PD). The effect of exercise to improve gait has been widely examined, often with special intervention. However, in clinical settings, physiotherapy rarely consists only of gait training.

OBJECTIVE: To examine whether versatile physiotherapy intervention conducted in accordance with European Physiotherapy Guideline for Parkinson's Disease (EPGPD) is sufficient to increase gait speed (GS).

METHODS: Participants (24) with idiopathic PD were randomly enrolled into intervention (IG) and control groups (CG) $(n=12,7$ females and 5 males in each group). Sixteen one-hour therapy sessions (twice per week) were conducted for IG. Each session focused on core areas recommended in EPGPD. Participants were assessed twice with 10 weeks between assessments. GS was calculated based on a gait test of Short Physical Performance Battery. Dominant side hip flexion and abduction range of motion (HFLEX \& HABD) were measured and Freezing of Gait questionnaire (FOG) was administered. RESULTS: Versatile intervention in groups resulted in increase of GS (ES - $0.9[\mathrm{CI}\{0.1\}-\{0.4\}] \mathrm{m} / \mathrm{s}$ ) and HFLEX (ES-0.6 $\left[\mathrm{CI}\{5.9\}-\left\{16.6^{\circ}\right\}\right]$. FOG was reduced (ES -0.41 [CI $\left.\left.\{-2.8\}\{-5.5\}\right]\right)$. Re-evaluation HABD differed between groups and indicated large ES $(r=-0.5)$.
\end{abstract}

CONCLUSIONS: Versatile physiotherapy is sufficient to improve GS, range of motion and reduce FOG.

Keywords: Parkinson's disease, gait speed, physiotherapy

\section{Introduction}

Parkinson's disease (PD) is a progressive disorder (Poewe et al., 2017) associated with a wide number of symptoms, including rigidity, bradykinesia, flexed posture, and freezing (Jankovic, 2008). Consequently, the quality of life of patients with PD

\footnotetext{
*Address for correspondence: Kadri Medijainen, Institute of Sport Sciences and Physiotherapy, University of Tartu, Ujula 42007, Tartu, Tartumaa, 51008, Estonia Tel.: +372 5549 719; E-mail: kadri.medijainen@ut.ee.
}

is considerably reduced (Louis \& Machado, 2015; Schrag, Jahanshani \& Quinn, 2000). Manifestations of PD affect various aspects of life, including the ability to transfer and walk, resulting in disability (Shulman, 2010). Therefore, patients with PD are often referred to physiotherapy. The European Physiotherapy Guideline for Parkinson's disease (EPGPD) (Keus et al., 2014) recommends referral to physiotherapy from the onset of the disease. To enhance the quality of life of patients with PD, the role of physiotherapy is to maximize functional ability, 
independence, safety, and wellbeing, thereby minimizing secondary complications, and also addressing fear of falling and maintenance of physical activity (Keus et al., 2014; Thomlinson et al., 2014).

Differences in gait parameters (e.g. cadence, stance and swing duration, stride length) between individuals with PD and controls have been widely reported (Hackney \& Earhart, 2009; Pistacci et al., 2017). Consequently, GS has also been one of the features used extensively in research on patients with PD (Nadeau, Poucher \& Corbeil, 2014; Pellechia et al., 2004; Rochester et al., 2010). GS has been the most commonly used outcome measure to assess the efficacy of an intervention programme.

Most available scientific literature has reported a positive effect of specific intervention programmes (e.g. gait training with usage of cueing (Rochester, et al. 2010) or treadmill training (Nadeau et al., 2014) or even tango (Blandy, Beevers, Fitzmaurice \& Morris, 2015).

In clinical settings physiotherapists are expected to provide versatile intervention to address all problems that PD patients encounter, not just gait issues. According to EPGPD (Keus et al., 2014), the core areas that should be included in any intervention are the following: physical capacity, transfers, manual activities, balance, and gait. To cover all the mobility concerns, physiotherapists must conduct comprehensive therapy with a duration suitable for the clinical setting.

In clinical settings it is not realistic to carry out therapy sessions that target merely one aspect of motor performance, which is often the requirement in research. The available literature leaves clinicians with a lack of knowledge about whether interventions that include and combine different evidence-based means of treatment will result in similar improvements that targeted exercise programs produce. The main aim of the current study is to examine the effect of comprehensive, guideline-based (Keus et al., 2014) physiotherapy in small groups on gait speed (GS) in individuals with PD. In addition, therapy's effect on freezing of gait (FOG) and range of motion (ROM), both known contributors of PD gait, are examined.

\section{Materials and methods}

\subsection{Participants}

Fifty individuals, who, according to an epidemiological database of PD patients, resided in the city
Table 1

Comparison of clinical and demographic characteristics of the participants at baseline

\begin{tabular}{lccc}
\hline Variable & $\begin{array}{c}\text { IG }(n=12) \\
\text { Mean (SD) }\end{array}$ & $\begin{array}{c}\text { CG }(n=12) \\
\text { Mean (SD) }\end{array}$ & $p$ value \\
\hline Age, years & $71.1(4.2)$ & $69.9(5.1)$ & 0.54 \\
Disease duration, years & $8.0(6.9)$ & $7.7(5.4)$ & 0.93 \\
HY stage & $2.2(0.5)$ & $2.3(0.7)$ & 0.93 \\
MDS-UPDRS total score & $62.2(21.5)$ & $60.4(26.7)$ & 0.86 \\
MDS-UPDRS motor score & $39.1(14.7)$ & $36.4(18.4)$ & 0.69 \\
MMSE score & $28.0(1.9)$ & $27.2(1.5)$ & 0.24 \\
Height, cm & $165.1(10.4)$ & $166.6(10.1)$ & 0.72 \\
Bodyweight, kg & $72.8(14.7)$ & $78.1(14.6)$ & 0.39 \\
\hline
\end{tabular}

IG: intervention group; CG: control group; SD: standardeviation; HY: Hoehn \& Yahr Scale; MDS - UPDRS: Movement Disorders Society Unified Parkinson Disease Rating Scale; MMSE: Mini Mental State Examination.

where the study was conducted (Tartu, Estonia) were contacted by telephone and asked to participate (convenience sampling).

Twenty-four patients (14 women and 10 men) met the inclusion criteria: (1) diagnosis of mild-tomoderate idiopathic PD according to the Hoehn \& Yahr Scale (HY); (2) aged over 60 and under 81 years old; (3) able to walk without an assistive device in their home setting (usage of assistive device for community-based ambulation was not an exclusion criteria); (4) no other untreated medical conditions that might affect gait or postural stability; (5) no participation in physiotherapy during the previous year; and (6) a Mini Mental State Examination (MMSE) score above 24 . Randomized block design was used to assign the participants to either the intervention group (IG, $n=12$ ) or control group (CG, $n=12$ ) (7 females and 5 males in both groups). Table 1 illustrates the demographic characteristics and clinical parameters of the participants during baseline assessment.

This study was carried out in compliance with the Helsinki declaration and has been approved by the Research Ethics Committee of the University of Tartu and registered in Tartu University's Clinical Research Database (No. 12125), with all participants having provided informed consent.

\subsection{Procedure}

Six researchers participated in data collection. Data was collected twice: at baseline and 10 weeks after the first assessment (and within a week after the intervention) at the Institute of Sport Sciences and Physiotherapy of University of Tartu, Estonia.

The procedure began with a patient interview. The same researcher interviewed the same patient 
during both data collections. The interview preceded the neurological examination by few days and was conducted at the patient's home. The interview included items of medical anamnesis (the course of the disease, medications) and social anamnesis, and the administration of the FOG questionnaire. During the interview, the participant was provided with the necessary information (e.g. appropriate clothing) about the functional assessment, and testing time was scheduled to ensure that the patient in the "on" phase during the functional assessment.

Neurological assessment involving the Hoehn \& Yahr Scale (HY), Movement Disorders Society Unified Parkinson's Disease Rating Scale (MDSUPDRS), and assessment of current cognitive status on MMSE was conducted by two blinded movement disorder experts during the baseline assessment.

Three assessors, uninformed about the group assignment, were always present during functional assessment to ensure the safety of patients. Possible bias among assessors was avoided by having the same assessor provide instructions and perform assessments (e.g. ROM measurement) per each participant during both data collections.

Functional assessment was comprised of the Short Physical Performance Battery (SPPB) and assessment of dominant-side hip joint flexion (HFLEX) and hip abduction motion (HABD). The ROM assessment was performed with the patient supine on a therapy plinth. SPPB was assessed according to the standard protocol (Guralnik et al., 1994). The duration of the 3-meter gait test (SPPB time) and corresponding GS, duration of 5-time sit-to-stand test (SPPB_chair) and total score (SPPB-tot) were used for data analysis (using the average between two trials of temporal parameters). GS was the primary outcome measure of the study.

All assessments were performed while patients received their usual antiparkinsonian medication during the "on" phase.

\subsection{Physical therapy}

The IG participated in sixteen sessions of physical therapy (twice per week) conducted by a specialist in neurological physiotherapy. Intervention was carried out in 4 groups ( 3 participants in each) in at the Tartu University Hospital. Intervention was started within a week of baseline assessment. The furnishing of the therapy room included three wide therapy plinths of adjustable height (to practice various transfers) and wall mirrors to gain feedback on body position- ing/alignment and exercise performance. A $20 \mathrm{~m}$ long and $3.5 \mathrm{~m}$ wide hallway was used during the gait training. All members of the IG participated in $100 \%$ of the physical therapy sessions.

Physiotherapy sessions with a duration of hour focused on five core areas of PD according to the EPGPD (Keus et al., 2014): physical capacity, transfers, manual activities, balance and gait. In addition, posture, ROM, and stretching exercises were carried out. Cognitive strategies, as well as visual and auditory cueing were used during therapy where appropriate. If required, assistance (including manual facilitation techniques when needed) was provided to ensure the correct performance of each exercise. Each session was divided into five parts: exercises in a) laying, b) sitting, c) standing, d) gait training, and e) hand function/manual dexterity. A short description of the structure and content of physiotherapy sessions is provided in Appendix 1. Each session of the first physiotherapy group was recorded and used as a basis for the other groups to ensure a similar intervention across groups. CG participants were scheduled for physiotherapy intervention after the second assessment.

\section{Data analysis}

Analysis was performed using commercially available software (SPSS 20.0, IBM, Armonk, USA). Descriptive analysis and normality testing (Shapiro-Wilk test) were conducted. In the case of a normal distribution of parametric variables, the functional performance of the IG and CG were compared using the student $t$-test, and the in-group comparison of baseline and post-intervention assessment utilized a paired $t$-test. In other cases, the Wilcoxon Signed Ranks test or Mann-Whitney U-test were used. The significance level was set at $p<0.05$. The effect size was calculated based on the coefficient of the product-moment correlation (r) (Tellez, Garcia \& Corral-Verdugo, 2015). The coefficient of the product-moment correlation was chosen to allow comparison between parametric and non-parametric data.

\section{Results}

The results of the study are based on the original groups, as there were no dropouts from the study from either group. At baseline, the IG and CG did not differ in the means of demographic characteristics and 
clinical parameters (see Table 1). Groups were similar in respect to their functional performance during baseline assessment.

During baseline assessment, for some of the outcome measures, a small between group ES was found, despite no statistical differences. However, we consider this group to be irrelevant to the main results, as univariate analysis did not reveal a group effect for any of the outcome measures. Also, within-group ES distinctly differ between groups and indicate improved performance in the IG. The results reveal statistically significant post-intervention improvement in SPPB time, GS, HFLEX, HABD and score of FOG questionnaire (see Table 2). Based on the confidence intervals (CI), the change of GS, HFLEX and
FOG score can be considered reliable. The change of FOG score also showed a significant group effect as did the between-group comparisons of SPPB_time, GS and HABD during re-evaluation. The latter also differed statistically between groups, as did the duration of SPPB_chair during re-evaluation.

When looking at the within-group ES (Table 2) based on $r$-values, a large effect was detected in IG for SPPB_time, GS and HFLEX, whereas the effect was moderate for the HABD and FOG scores. The withingroup ES was also moderate in CG for SPPB_time and small for GS and HFLEX. Between-group ES increased post-intervention (Table 3), being at least near-moderate (FOG score and SPPB_tot) to large (HABD).

Table 2

Functional performance and treatment effect among the IG and CG

\begin{tabular}{|c|c|c|c|c|c|c|c|c|}
\hline \multirow[b]{2}{*}{ Variable } & \multirow[b]{2}{*}{ Group } & \multicolumn{4}{|c|}{ Before vs after } & \multicolumn{3}{|c|}{ Mean change } \\
\hline & & $\begin{array}{c}\text { Before } \\
\text { mean }(\mathrm{SD})\end{array}$ & $\begin{array}{c}\text { After } \\
\text { mean (SD) }\end{array}$ & ES & $\overline{p \text { value }}$ & $\begin{array}{l}\text { Mean } \\
\text { change }\end{array}$ & $\begin{array}{c}\text { Lower } \\
\text { bound CI }\end{array}$ & $\begin{array}{c}\text { Upper } \\
\text { bound CI }\end{array}$ \\
\hline \multirow[t]{2}{*}{ SPPB_time, sec } & IG & $3.3(1.1)$ & $2.5(0.5)$ & -0.50 & 0.015 & $-0.8 *$ & -1.3 & 0.3 \\
\hline & CG & $3.5(1.0)$ & $3.0(0.9)$ & -0.36 & 0.077 & -0.5 & -1.2 & 0.1 \\
\hline \multirow[t]{2}{*}{$\mathrm{GS}, \mathrm{m} / \mathrm{s}$} & IG & $1.0(0.3)$ & $1.3(0.3)$ & -0.85 & 0.002 & $0.3 *$ & 0.1 & 0.4 \\
\hline & CG & $0.9(0.3)$ & $1.0(0.3)$ & -0.22 & 0.304 & 0.1 & -0.1 & 0.3 \\
\hline \multirow[t]{2}{*}{ SPPB_chair, sec } & IG & $10.7(7.5)$ & 8.8(3.7)\# & -0.22 & 0.286 & -1.9 & -5.1 & 1.3 \\
\hline & CG & $14.6(11.1)$ & $12.0(3.7)$ & -0.06 & 0.754 & -2.6 & -8.9 & 3.4 \\
\hline \multirow[t]{2}{*}{ SPPB_tot, points } & IG & $10.8(2.4)$ & $11.3(1.2)$ & -0.13 & 0.518 & 0.5 & -0.7 & 1.7 \\
\hline & CG & $10.6(1.5)$ & $10.5(1.5)$ & -0.09 & 0.655 & -0.1 & -1.0 & 0.9 \\
\hline \multirow{2}{*}{$\mathrm{HFLEX}^{\circ}{ }^{\circ}$} & IG & $122.5(12.5)$ & $133.8(6.6)$ & -0.61 & 0.003 & $11.3 *$ & 5.9 & 16.6 \\
\hline & CG & $124.3(15.8)$ & $125.5(20.5)$ & -0.23 & 0.255 & 0.2 & -17.1 & 19.4 \\
\hline \multirow[t]{2}{*}{$\mathrm{HABD},{ }^{\circ}$} & IG & $21.3(5.6)$ & $24.2(2.5) \#$ & -0.42 & 0.039 & $2.9^{*}$ & -0.9 & 6.7 \\
\hline & CG & $20.3(5.6)$ & $20.2(3.8)$ & -0.08 & 0.694 & -0.1 & -4.2 & 40.0 \\
\hline \multirow[t]{2}{*}{ FOG, points } & IG & $7.4(6.1)$ & $4.7(3.9)$ & -0.41 & 0.043 & $-2.8^{*}$ & -5.5 & -0.1 \\
\hline & CG & $5.8(3.6)$ & $5.9(3.3)$ & -0.03 & 0.888 & 0.1 & -1.4 & 1.5 \\
\hline
\end{tabular}

IG: intervention group; CG: control group; SD: standard deviation; ES: effect size according to coefficient of product-moment correlation (r); CI: confidence interval; SPPB_time: duration of gait test of Short Performance Battery (SPB); GS: standing to walking transition gait speed calculated based on SPPB gait test performance SPPB_chair: duration of sit-to-stand-test of SPPB; SPPB_tot: total score of SPPB; HFLEX: dominant side hip flexion range of motion; ${ }^{\circ}$ : degree; HABD: dominant side hip abduction range; FOG: Score of Freezing of Gait Questionnaire; * significant difference between baseline and re-evaluation value on a level of $p<0.05$; \# significant difference between IG and CG.

Table 3

Level of significance for gender and group main effect and interaction effect

\begin{tabular}{|c|c|c|c|c|c|c|c|c|c|}
\hline \multirow[b]{3}{*}{ Variable } & \multicolumn{3}{|c|}{ Baseline assessment } & \multicolumn{3}{|c|}{ Re-evaluation } & \multicolumn{3}{|c|}{ Change } \\
\hline & \multicolumn{2}{|c|}{ Main effect } & \multirow{2}{*}{$\begin{array}{c}\text { Interaction } \\
\text { effect }\end{array}$} & \multicolumn{2}{|c|}{ Main effect } & \multirow{2}{*}{$\begin{array}{c}\text { Interaction } \\
\text { effect }\end{array}$} & \multicolumn{2}{|c|}{ Main effect } & \multirow{2}{*}{$\begin{array}{c}\text { Interaction } \\
\text { effect }\end{array}$} \\
\hline & Group & Gender & & Group & Gender & & Group & Gender & \\
\hline SPPB_time, sec & 0.58 & 0.24 & 0.79 & $0.05^{*}$ & 0.81 & 0.16 & 0.35 & 0.20 & 0.16 \\
\hline $\mathrm{GS}, \mathrm{m} / \mathrm{s}$ & 0.57 & 0.31 & 0.83 & $0.02 *$ & 0.62 & 0.06 & 0.06 & 0.55 & 0.41 \\
\hline SPPB_chair, sec & 0.48 & 0.48 & 0.06 & 0.08 & 0.98 & 0.12 & 0.98 & 0.38 & 0.12 \\
\hline SPPB_tot, points & 0.73 & 0.20 & 0.40 & 0.17 & 0.20 & 0.70 & 0.51 & 0.63 & 0.51 \\
\hline HFLEX, ${ }^{\circ}$ & 0.85 & 0.54 & 0.52 & 0.24 & 0.46 & 0.67 & 0.33 & 0.90 & 0.47 \\
\hline $\mathrm{HABD},{ }^{\circ}$ & 0.63 & 0.70 & 0.67 & 0.01 & 0.78 & 0.81 & 0.32 & 0.84 & 0.62 \\
\hline FOG, points & 0.47 & 0.80 & 0.93 & 0.36 & 0.83 & 0.46 & $0.05^{*}$ & 0.88 & 0.37 \\
\hline
\end{tabular}

SPPB_time: duration of gait test of Short Performance Battery (SPB); GS: standing to walking transition gait speed calculated based on SPPB gait test performance SPPB_chair: duration of sit-to-stand-test of SPPB; SPPB_tot: total score of SPPB; HFLEX: dominant side hip flexion range of motion; ${ }^{\circ}$ : degree; HABD: dominant side hip abduction range; FOG: Score of Freezing of Gait Questionnaire; *statistically significant main and/or interaction effect on a level of $p<0.05$. 


\section{Discussion}

The results of our study indicate that two months of comprehensive physiotherapy in groups, including ten minutes of gait training per session, is sufficient to improve GS. We argue that the improved GS among the IG is at least partly due to increased ROM (mean improvement of HABD and HFLEX 11.5\%, whereas in the CG the change was less than $1 \%$ ). We believe that the increased ROM also reflects reduced rigidity and is the result of the stretching and $\mathrm{ROM}$ exercises performed in therapy. Rigidity is known to be associated with a reduction in arm and leg swing during gait (Kwon et al., 2014), thereby influencing gait. Therefore, the increased ROM is likely to be an important contributor to the improvement of GS of IG. Cristiansen (2008) also reported that stretching exercises increased GS.

Gait initiation failure is a component of FOG (McCandless et al., 2016), and has been reported to occur in up to $86 \%$ of PD patients (Giladi et al., 1992). GS, which was assessed in the current study, includes gait initiation and was significantly improved in IG, indicating, in our opinion, reduced start hesitation and improved gait initiation. This is further supported by the score of the FOG questionnaire, which was significantly lower post-intervention (relative mean change of $37.1 \%$ ) in IG. Based on the improvements seen in ROM during the intervention period and on re-evaluation, we argue that improved lumbar and pelvic girdle mobility (which were addressed during the intervention) provide an important contribution to reduction of FOG. Future studies will hopefully provide more evidence to support this.

The therapy provided in the current study addressed the core areas recommended in EPGPD (Keus et al., 2014) and the exercises were chosen to influence different aspects of motor performance. We consider this to be one of the strengths of the study, as patients with PD can encounter a number of difficulties with movement that cannot be sufficiently addressed by use of only one type of intervention, e.g. only gait training or balance exercises. Adequate alignment of body segments and postural control are two factors needed for all motor performance abilities. Both of these factors are known to be disturbed due to PD (Blaszczyk, Orawiece, Duda-Klodowska \& Opala, 2007; Revuelta, 2012), and therefore the need to apply postural correction and postural control exercises in therapy programmes is apparent, and were included in the therapy.
Future research should study the impact of diverse interventions in divergent way, focusing on different aspects of motor performance. Our study measured the impact of comprehensive physiotherapy on gait function, more specifically during standing-to-walking transition (including gait initiation). It is likely that the gait training included in our study is not sufficient to improve gait function associated with all the circumstances occurring in everyday life (e.g. walking fast, sideways, backwards, etc.).

The moderate within-group ES of SPPB_time and small ES of GS found in CG could be associated with usage of an "attention strategy" resulting in faster performance. A study by Baker, Rochester \& Nieuwboer (2007) also found that, among other cueing strategies, "attentional strategies" can be beneficial in improving the gait of PD patients. Another possible explanation for the improvement of GS in CG members who did not participate in any intervention could be learning or retest effect. Behrman, Cauraugh \& Light (2000) reported the learning effect in improving movement speed in PD patients.

Conducting therapy in groups instead of individually could also have influenced our results. Park et al. (2014) reported that group therapy helped to improve attitudes and fostered optimism among patients with PD. The $100 \%$ participation rate in therapy sessions in our study indicates that participants were not reluctant and found the therapy environment to be pleasant. The small group size (three persons) enabled the physiotherapist to ensure correct exercise performance of all participants by providing manual facilitation when needed. In addition, practicing inbed transfers on a wide plinth was possible, which is usually not an option with larger groups. This possibly contributed to the considerable improvement of ROM. Future research is needed to clarify the impact of similar therapy programme in the case of larger groups or in the form of individual therapy. Further, the current study was conducted with patients with mild-to-moderate PD. A study with patients with more advanced PD is needed to determine whether intervention results in similar beneficial effects. However, we consider groups of three to four people to be most cost-effective, as well as providing sufficient individualized physiotherapeutic attention to the patient and embracing the positive aspects of group therapy.

We acknowledge the limitations of our study, mainly arising from the small sample size, which reduces the generalisability of the results. However, we believe that we have considered this aspect suf- 
ficiently in our statistical analysis and have been conservative in our interpretation of the results. In addition, as some gender differences in the clinical presentation of PD (Baba, Putzke, Whaley, Wszolek \& Uitti, 2005) and treatment outcome (Hariz, Linberg, Hariz \& Bergenheim, 2003) have already been reported in the available literature, we are convinced that gender as a contributing factor in the actual performance and intervention outcomes needs more attention in future research. Future studies should also compare the duration of effect of similar interventions.

We consider the main strength of this study to be its use of a versatile physical therapy intervention. The assessment used can easily be used in any setting and the therapy was conducted in such a way that it could be reproduced in other settings.

\section{Conclusion}

Our study revealed that a comprehensive, twomonth guideline-based group physiotherapy intervention is beneficial for improving GS during the standing-to-walking transition. In addition, this versatile intervention results in increased ROM and reduced FOG.

\section{Acknowledgments}

This study was supported by the grants PUT1239 and IUT2-4 from the Estonian Research Council. The authors wish to acknowledge the physiotherapists Kristi Reimann, Mari Raudmann and Kristel Ao for their help in data collection. We also express our gratitude to Mikk Medijainen who provided valuable feedback.

\section{Conflict of interest}

The authors declare that there are no conflicts of interest regarding the publication of this paper.

\section{References}

[1] Poewe, W., Seppi, K., Tanner, C. M., Halliday, G. M., Brundin, P., Volkmann, J. et al. (2017). Parkinson disease. Nat Rev Dis Primers, 3, 17013.

[2] Jankovic, J. (2008). Parkinson's disease: Clinical features and diagnosis. J Neurol Neurosurg Psychiatry, 79, 368-376.

[3] Louis, E. D., \& Machado, D. G. (2015). Tremor-related quality of life: A comparison of essential tremor vs.
Parkinson's disease patients. Parkinsonism and Relat Disord, 21, 729-735.

[4] Schrag, A., Jahanshahi, M., \& Quinn, N. (2000). What contributes to quality of life in patients with Parkinson's disease? J Neurol Neurosurg Psychiatry, 69, 308-312.

[5] Shulman, L. M. (2010). Understanding Disability in Parkinson's Disease. Mov Disord, 25(Suppl 1), S131-S135.

[6] Keus, S. H. J., Munneke, M., Graziano, M., Paltamaa, J., Pelosin, E., Domingos, J. et al. (2014). European Physiotherapy Guideline for Parkinson's disease. KNGF/ParkinsonNet, the Netherlands.

[7] Thomlison, C. L., Herd, C. P., Clarke, C. E., Meek, C., Patel, S., Stowe, R. et al. (2014). Physiotherapy for Parkinson's disease: A comparison of techniques. Cochrane Database Syst Rev, (6), CD002815.

[8] Pistacci, M., Gioulis, M., Sanson, F., De Giovannini, E., Filippi, G., Rosetto, F., \& Marsala, S. Z. (2017). Gait analysis and clinical correlations in early Parkinson's disease. Funct Neurol, 32(1), 28-34.

[9] Hackney, M. E., \& Earhart, G. M. (2009). Backward walking in Parkinson's disease. Mov Disord, 24(2), 218-223.

[10] Pellechia, M. T., Grasso, A., Biancardi, L. G., Squillante, M., Bonavita, V., \& Barone P. (2004). Physical therapy in Parkinson's disease: An open long-term rehabilitation trial. J Neurol, 251, 595-598.

[11] Rochester, L., Baker, K., Hetherington, V., Jones, D., Willems, A. M., Kwakkel, G. et al. (2010). Evidence for motor learning in Parkinson's disease: Acquisition, automaticity and retention of cued gait performance after training with external rhythmical cues. Brain Res, 1319, 103-111.

[12] Nadeau, A., Pourcher, E., \& Corbeil, P. (2014). Effects of 24 wk of treadmill training on gait performance in Parkinson's disease. Med Sci Sports Exerc, 46(4), 645-655.

[13] Blandy, L. M., Beevers, W. A., Fitzmaurice, K., \& Morris M. (2015). Therapeutic argentine tango dancing for people with mild Parkinson's disease: A feasibility study. Front Neurol, 6, 122 (1-7).

[14] Guralnik, J. M., Simonsick, E. M., Ferrucci, L., Glynn, R. J., Berkman, L. F., Blazer, D. G., et al. (1994). A Short Physical Performance Battery Assessing Lower Extremity Function: Association With Self-Reported Disability and Prediction of Mortality and Nursing Home Admission. J Gerontol, 49(2), M85-94.

[15] Tellez, A., Garcia, C. H., \& Corral-Verdugo V. (2015). Effect size, confidence intervals and statistical power in psychological research. Psychology in Russia: State of the Art, 8(3), 27-47.

[16] Kwon, K. Y., Kim M, Lee, S. M., Kang, S. H., Lee, H. M., \& Koh, S. B. (2014). Is reduced arm and leg swing in Parkinson's disease associated with rigidity or bradykinesia? $J$ Neurol Sci, 341(1-2), 32-35.

[17] Christiansen, C. L. (2008). The effects of hip and ankle stretching on gait function of older people. Arch Phys Med Rehabil, 89, 1421-1428.

[18] McCandless, P. J., Evans, B. J., Janssen, J., Selfe, J., Churchill, A., \& Richards J. (2016). Effect of three cueing devices for people with Parkinson's disease with gait initiation difficulties. Gait Posture, 44, 7-11

[19] Giladi, N., McMahon D, Przedborski, S., Flaster, E., Guillory S, Kostic, V. et al. (1992). Motor blocks in Parkinson's disease. Neurology, 42, 333-339.

[20] Revuelta, G. J. (2012). Anterocollis and camptocormia in parkinsonism: A current assessment. Curr Neurol Neurosci Rep, 12(4), 386-391. 
[21] Blaszczyk, J. W., Orawiec R, Duda-Klodowska, D., \& Opala G. (2007). Assessment of postural instability in patients with Parkinson's disease. Exp Brain Res, 183(1), 107-114.

[22] Baker, K., Rochester, R., \& Nieuwboer, A. (2007). The immediate effect of attentional, auditory, and a combined cue strategy on gait during single and dual tasks in Parkinson's disease. Arch Phys Med Rehabil, 88(12), 1593-1600.

[23] Behrman, A. L., Cauraugh, J. H., \& Light, K. E. (2000). Practice as an intervention to improve speeded motor performance and motor learning in Parkinson's disease. J Neurol Sci, 174, 127-136.

[24] Park, A., Zid, D., Russell, J., Malone, A., Rendon, A., Wehr, A. et al. (2014). Effects of a formal exercise program on Parkinson's disease: A pilot study using a delayed start design. Parkinsonism Relat Disord, 20(1), 106-111.
[25] Baba, Y., Putzke, J. D., Whaley, N. R., Wszolek, Z. K., \& Uitti, R. J. (2005). Gender and the Parkinson's disease phenotype. J Neurol, 252(10), 1201-1205.

[26] Hariz, G. M., Lindberg, M., Hariz, M. I., \& Bergenheim, A. T. (2003). Gender differences in disability and healthrelated quality of life in patients with Parkinson's disease treated with stereotactic surgery. Acta Neurol Scand, 108(1), 28-37. 
Appendix 1

The structure of the physiotherapy sessions

\begin{tabular}{|c|c|c|c|c|c|}
\hline & \multicolumn{5}{|c|}{ Different sections of each physiotherapy session } \\
\hline & $\begin{array}{l}\text { Exercises in a laying } \\
\text { position (supine, } \\
\text { prone, and } \\
\text { side-laying) }\end{array}$ & $\begin{array}{l}\text { Exercises in a sitting } \\
\text { position }\end{array}$ & $\begin{array}{l}\text { Exercises in a } \\
\text { standing position } \\
\text { (including cues } \\
\text { where appropriate } \\
\text { and visual } \\
\text { feedback) } \\
\end{array}$ & $\begin{array}{l}\text { Gait training } \\
\text { (including different } \\
\text { cues where } \\
\text { appropriate and } \\
\text { visual feedback) }\end{array}$ & $\begin{array}{l}\text { Exercises for hand } \\
\text { function and } \\
\text { manual dexterity }\end{array}$ \\
\hline \multirow{7}{*}{$\begin{array}{l}\text { Duration } \\
\text { Purpose and target of } \\
\text { the exercises } \\
\text { performed }\end{array}$} & 15 minutes & 10 minutes & 15 minutes & 10 minutes & 10 minutes \\
\hline & $\begin{array}{l}\text { - Improving the } \\
\text { quality of } \\
\text { movement and } \\
\text { reducing the } \\
\text { duration needed to } \\
\text { execute in-bed } \\
\text { transfers (e.g. } \\
\text { rolling from supine } \\
\text { to side-laying, } \\
\text { rolling from supine } \\
\text { to prone etc) and } \\
\text { transfers from } \\
\text { laying-to-sitting and } \\
\text { vice versa. }\end{array}$ & $\begin{array}{l}\text { - Improving the } \\
\text { quality of } \\
\text { movement and } \\
\text { reducing the } \\
\text { duration needed to } \\
\text { execute } \\
\text { sitting-to-standing } \\
\text { and } \\
\text { standing-to-sitting } \\
\text { transfers and } \\
\text { scooting } \\
\text { movements in } \\
\text { sitting position }\end{array}$ & $\begin{array}{l}\text { - Improving standing } \\
\text { posture. }\end{array}$ & $\begin{array}{l}\text { - Improving gait } \\
\text { initiation }\end{array}$ & $\begin{array}{l}\text { - Improving manual } \\
\text { dexterity (including } \\
\text { different bilateral } \\
\text { and unilateral } \\
\text { activities with the } \\
\text { need of using } \\
\text { different grasp } \\
\text { types). }\end{array}$ \\
\hline & $\begin{array}{l}\text { Improving range of } \\
\text { motion (e.g. spinal, } \\
\text { neck, shoulder, hip, } \\
\text { knee), incorporating } \\
\text { stretching exercises } \\
\text { (e.g. hamstrings, } \\
\text { pectoral muscles, } \\
\text { neck muscles). }\end{array}$ & $\begin{array}{l}\text { Improving spinal } \\
\text { range of motion }\end{array}$ & $\begin{array}{l}\text { - Improving weight } \\
\text { transference }\end{array}$ & $\begin{array}{l}\text { - Increasing step } \\
\text { length }\end{array}$ & $\begin{array}{l}\text { - Improving range of } \\
\text { motion of upper } \\
\text { limbs }\end{array}$ \\
\hline & $\begin{array}{l}\text { Muscle } \\
\text { strengthening (e.g. } \\
\text { spinal extensors, } \\
\text { knee and hip } \\
\text { extensors, hip and } \\
\text { knee flexors, } \\
\text { abductors). }\end{array}$ & $\begin{array}{l}\text { - Improving sitting } \\
\text { posture }\end{array}$ & $\begin{array}{l}\text { - Improving static } \\
\text { balance (including } \\
\text { exercises with eyes } \\
\text { closed. }\end{array}$ & $\begin{array}{l}\text { - Improving gait } \\
\text { speed. }\end{array}$ & $\begin{array}{l}\text { - Muscle } \\
\text { strengthening of } \\
\text { upper limbs. }\end{array}$ \\
\hline & & $\begin{array}{l}\text { - Muscle } \\
\text { strengthening (e.g. } \\
\text { spinal/thoracic } \\
\text { extensors, hip } \\
\text { flexors). }\end{array}$ & $\begin{array}{l}\text { - Improving gait } \\
\text { initiation. }\end{array}$ & $\begin{array}{l}\text { - Improving } \\
\text { reciprocal upper } \\
\text { limb movement } \\
\text { during gait. }\end{array}$ & \\
\hline & & & $\begin{array}{l}\text { - Muscle } \\
\text { strengthening. } \\
\text { - Improving dynamic } \\
\text { balance (e.g. } \\
\text { practising turns in } \\
\text { place). }\end{array}$ & $\begin{array}{l}\text { - Muscle } \\
\text { strengthening of } \\
\text { lower limbs. } \\
\text { - Improving physical } \\
\text { capacity/endurance. }\end{array}$ & \\
\hline & & & & $\begin{array}{l}\text { - Improving dynamic } \\
\text { balance (e.g. } \\
\text { including turns } \\
\text { (U-turn), stepping } \\
\text { over obstacles, gait } \\
\text { with head turns, } \\
\text { etc.) }\end{array}$ & \\
\hline
\end{tabular}

